\title{
Oil Extraction from Rice Bran Using Expanded Liquid Hexane with $\mathrm{CO}_{2}$
}

\author{
Le Thi Thien LY ${ }^{1}$, Idzumi OKAJIMA ${ }^{1}$, Kong Chang YI ${ }^{1}$, and Takeshi SAKO ${ }^{2 *}$ \\ ${ }^{1}$ Graduate School of Integrated Science and Technology, Shizuoka University, 3-5-1 Johoku, Naka-ku, Hamamatsu, Shizuoka 432- \\ 8561, Japan \\ ${ }^{2}$ Graduate School of Science and Technology, Shizuoka University, 3-5-1 Johoku, Naka-ku, Hamamatsu, Shizuoka 432-8561, Japan
}

\begin{abstract}
Bio-oil is often extracted from biomass using liquid solvent or supercritical carbon dioxide. However, extraction using these methods has several disadvantages. In this study, expanded hexane with carbon dioxide is examined as a new extraction solvent. The objective of this study is to develop a new technique for the extraction of bio-oil from biomass using expanded hexane with carbon dioxide; rice bran is used as the raw biomass. The extraction was carried out at 25$27^{\circ} \mathrm{C}, 5.0-5.3 \mathrm{MPa}$, and $0.78-0.94$ mole fraction of carbon dioxide in expanded hexane. At $26^{\circ} \mathrm{C}$, $5.1 \mathrm{MPa}, 0.87$ of mole fraction of carbon dioxide, the oil yield was 1.6 times greater than that with normal liquid hexane because of the low viscosity and high permeability of expanded hexane. Furthermore, the phosphorus concentration in the extracted oil was $9.5 \mathrm{ppm}$. This was very low, compared with that in rice bran,in which it is approximately $350 \mathrm{ppm}$. This was because the solvent power of expanded hexane to extract neutral lipid decreased slightly while that to extract polar components decreased significantly. As a result, expanded hexane with carbon dioxide could extract the phosphorus-free bio-oil in high yield under mild conditions.
\end{abstract}

\section{Introduction}

Rice bran is the byproduct of milling paddy rice to produce refined rice. During milling, approximately $73.5 \%$ of white rice, $3.5 \%$ of broken rice, $15 \%$ of husk, and $8 \%$ of rice bran are obtained from paddy (Pandey and Shrivastava, 2018). Since rice bran contains $15-25 \mathrm{wt} \%$ oil and is one of the most abundant byproducts of the rice industry, it is an important biomass for producing bio-oil. However, it must be stabilized immediately upon production, primarily because of the presence of lipase, an enzyme that rapidly hydrolyzes oil to free fatty acids (FFA) and glycerol. The hydrolysis drastically degrades the quality of the rice bran (Lakkakula et al., 2004).

For the extraction of bio-oil from rice bran, two methods have been identified: extraction using (i) hexane and (ii) supercritical carbon dioxide $\left(\mathrm{SC}-\mathrm{CO}_{2}\right)$. Extraction with hexane can be conducted under atmospheric pressure and results in high oil extraction. However, this process has some limitations with respect to the oil quality. The hexane-extracted crude oil contains impurities such as phospholipids, free fatty acids, and wax, owing to the strong solvent power of hexane. On the other hand, supercritical carbon dioxide has many advantages, including tunable solvent properties, rapid mass transfer, facile removal of the solvent, and production of solventfree crude lipids (Halim et al., 2012). Therefore, this process can be used to extract impurity-free rice bran oil or other bio-oil in high yields. However, it requires high pressure at $20-40 \mathrm{MPa}$ and temperature of $40-60^{\circ} \mathrm{C}$ to obtain yields comparable with that by hexane extraction (Tomita et al., 2014).

In this study, expanded hexane with carbon dioxide is examined as a new extraction solvent. The solvent, which is diluted liquid hexane with carbon dioxide, has the combined properties of a compressed gas and liquid. In $\mathrm{CO}_{2}$-expanded liquid, $\mathrm{CO}_{2}$ not only reduces the volume of the organic solvent, hexane, required for the extraction but also decreases the solvent polarity. Therefore, this solvent has low solvent power and high selectivity for neutral lipids as compared with normal liquid hexane. Therefore, the expanded hexane is expected to dissolve non-polar oil but not polar oils such as phospholipids. This paper discusses the optimized parameters for the extraction of bio-oil with reduced phospholipids using the expanded liquid and for obtaining the maximum yield and quality of bio-oil for biodiesel production. The influence of the extraction conditions $\left(\mathrm{CO}_{2}\right.$ mole fraction, pressure, and amount of solvent) on the phospholipids content of the extracted oil and the solubility of bio-oil in the expanded liquid were studied. The following parameters affecting the quality of biodiesel have been taken into account: solubility, phosphorus concentration, and free fatty acids concentration. The goal is to produce bio-oil with a phosphorus concentration less than $20 \mathrm{ppm}$.

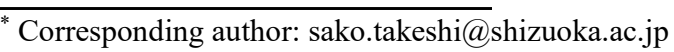




\section{Experimental}

\subsection{Materials}

Rice bran was obtained from Hamamatsu city (Japan) and stored in the freezer of a refrigerator during the investigation to avoid any change in the components. Before charging the extraction column, rice bran was sieved to remove unwanted particles such as broken rice and husk. Pressurized liquid carbon dioxide was provided by Air Liquid Hamamatsu. Hexane (96.0\%) was procured from FUJIFILM Wako Pure Chemical Corporation. The packing agents were round, perforated plastic beads with an average diameter of $4 \mathrm{~mm}$. The extraction column was made of stainless steel, with a volume of $180 \mathrm{~mL}$, length of $350 \mathrm{~mm}$, outer diameter of $34.1 \mathrm{~mm}$, and inner diameter of $29.8 \mathrm{~mm}$.

\subsection{Experimental procedure}

The phase diagram of hexane- $\mathrm{CO}_{2}$ at $25^{\circ} \mathrm{C}$ is shown in Figure 1. The red dots represent the experimental conditions in this study. The extraction was performed in the liquid phase or liquid-vapor two-phase region at 25$27^{\circ} \mathrm{C}$, and 5.0-5.3 MPa (Knapp et al., 1982).

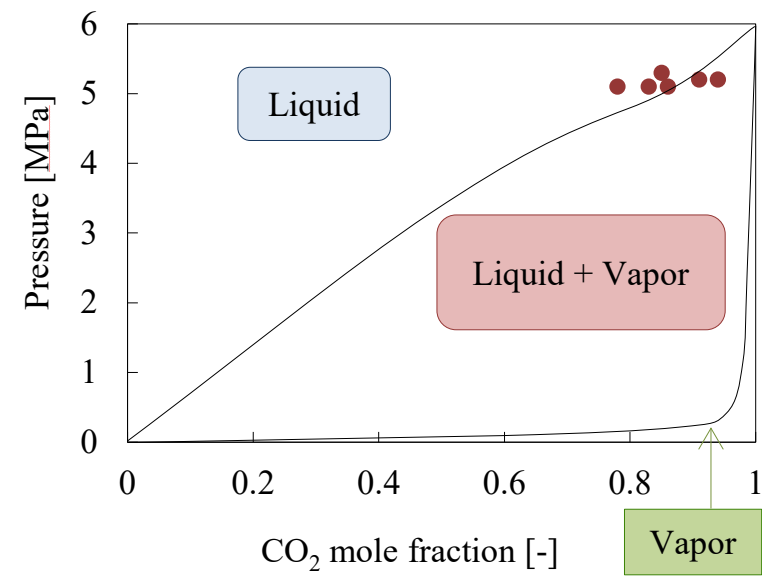

Figure 1. Phase diagram of $\mathrm{CO}_{2}$-hexane system at $25^{\circ} \mathrm{C}$

The oil extraction was performed using the apparatus shown in Figure 2. Rice bran $(50 \mathrm{~g})$ was loaded into the extraction column. Glass beads were placed on the top and bottom of the extraction column. The extraction column was sealed, heated, and pressurized until the desired operational conditions were achieved. Hexane and $\mathrm{CO}_{2}$ were pumped by a plunger pump and a cylinder pump, respectively, and mixed together before flowing into the extraction column. The pressure in the system was maintained by a backpressure regulator (BPR) and was read by a PE33-A Digital pressure gauge with an accuracy of $0.1 \%$. The extract exiting the BPR was collected in icecooled trap bottles at predetermined time intervals. Hexane was removed from the collected extract using a rotary evaporator at $45^{\circ} \mathrm{C}$ for about $30 \mathrm{~min}$. Finally, the oil was dried at $58^{\circ} \mathrm{C}$ in a drying machine until a constant weight was attained, thus confirming the elimination of traces of solvent and water.

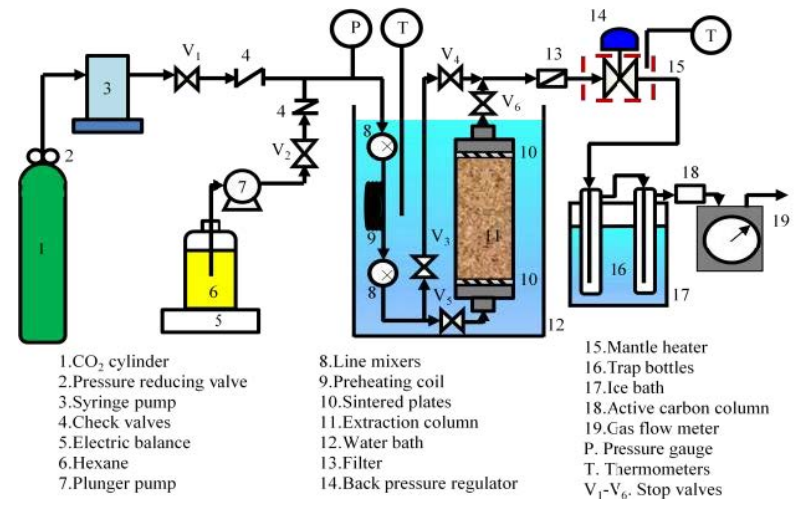

Figure 2. Experimental apparatus

The oil extraction using hexane was performed to initial oil contents in rice bran. Rice bran $(10 \mathrm{~g})$ and $100 \mathrm{~mL}$ solvent were used in all cases.

\subsection{Analytical procedure}

The solvent consumption per $1 \mathrm{~g}$ of rice bran was calculated from the flow rates of hexane and $\mathrm{CO}_{2}$. Extraction yields were expressed as the percentage of total extract obtained with respect to the mass of the rice bran. The horizontal axis represents the solvent consumption, and the vertical axis represents the extraction yield. The slope of the approximately straight line at the beginning of extraction gives the solubility of the bio-oil in the expanded liquid.

$$
\begin{aligned}
& \text { Solvent consumption }[\mathrm{g} / \mathrm{g}-\text { sample }] \\
& \qquad=\frac{\left(\text { Hexane }[\mathrm{g} / \mathrm{min}]+\mathrm{CO}_{2}[\mathrm{~g} / \mathrm{min}]\right) \times \text { Time }[\mathrm{min}]}{\text { Rice bran }[\mathrm{g}]} \\
& \text { Extraction yield }=\frac{\text { Extracted bio-oil }[\mathrm{g} / \mathrm{g}-\text { sample }]}{\text { Rice bran }[\mathrm{g}]}
\end{aligned}
$$

The phosphorus concentration was measured by inductively coupled plasma.

The acid value is expressed in $\mathrm{mg}$ of $\mathrm{KOH}$ required to neutralize the free fatty acids present in $1 \mathrm{~g}$ of extracted bio-oil.

\section{Results and Discussion}

Table 1 lists the experimental parameters, namely, temperature $(\mathrm{T})$, pressure $(\mathrm{P})$, and $\mathrm{CO}_{2}$ mole fraction and the solubility and phosphorus concentration $([\mathrm{P}])$.

\subsection{Bio-oil solubility measurement}

The relationship between the solvent consumption and the extraction yield of bio-oil at $26^{\circ} \mathrm{C}, 5.3 \mathrm{MPa}$ and 0.84 mole fraction of $\mathrm{CO}_{2}$ is shown in Figure 3. The slope of the approximate straight line at the beginning of extraction gives the solubility of bio-oil in the $\mathrm{CO}_{2}$ - expanded liquid, which was $0.1044 \mathrm{~g} / \mathrm{g}$-solvent under these conditions. 
Table 1. Experimental conditions, solubility of bio-oil, and phosphorus concentration

\begin{tabular}{|c|c|c|c|c|c|}
\hline Exp. No. & $\mathbf{T}\left[{ }^{\circ} \mathbf{C}\right]$ & $\mathbf{P}[\mathbf{M P a}]$ & $\mathbf{C O}_{2}$ mole fraction [-] & Solubility [g/g-solvent] & {$[\mathbf{P}]$ [ppm] } \\
\hline 1 & 25 & 5.1 & 0.78 & 0.1999 & 150.4 \\
\hline 2 & 27 & 5.1 & 0.82 & 0.1503 & 99.9 \\
\hline 3 & 26 & 5.3 & 0.84 & 0.1044 & 59.8 \\
\hline 4 & 26 & 5.1 & 0.87 & 0.0637 & 9.1 \\
\hline 5 & 25 & 5.2 & 0.91 & 0.0227 & 5.4 \\
\hline 6 & 25 & 5.2 & 0.94 & 0.0118 & 5.0 \\
\hline
\end{tabular}

The total extraction yield was $0.2297 \mathrm{~g} / \mathrm{g}$-sample, which was 1.2 times greater than the extraction yield obtained using normal liquid hexane $(0.1860 \mathrm{~g} / \mathrm{g}$-sample).

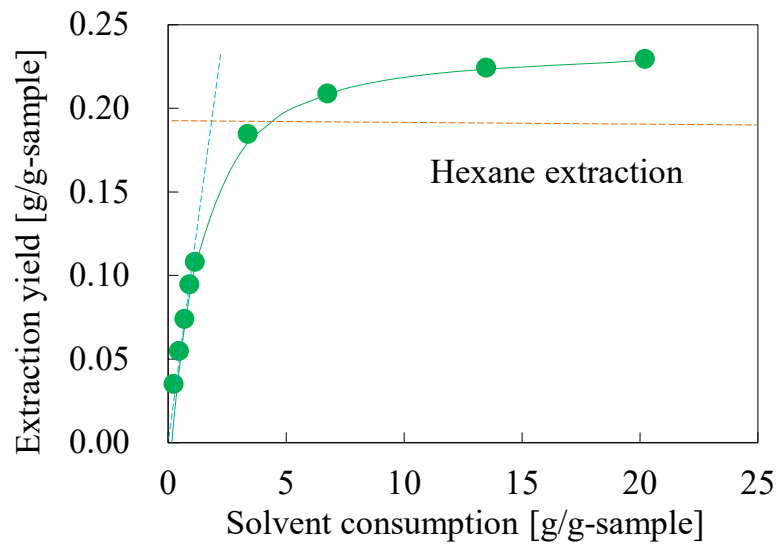

Figure 3. Extraction yield of bio-oil from rice bran using expanded hexane with $\mathrm{CO}_{2}$ at $26^{\circ} \mathrm{C}, 5.3 \mathrm{MPa}$, and 0.84 mole fraction of $\mathrm{CO}_{2}$

\subsection{Effect of $\mathrm{CO}_{2}$ mole fraction on solubility of bio-oil and phosphorus concentration}

The influence of $\mathrm{CO}_{2}$ mole fraction in the extractant on the solubility of bio-oil and phosphorus concentration is shown in Figure 4.

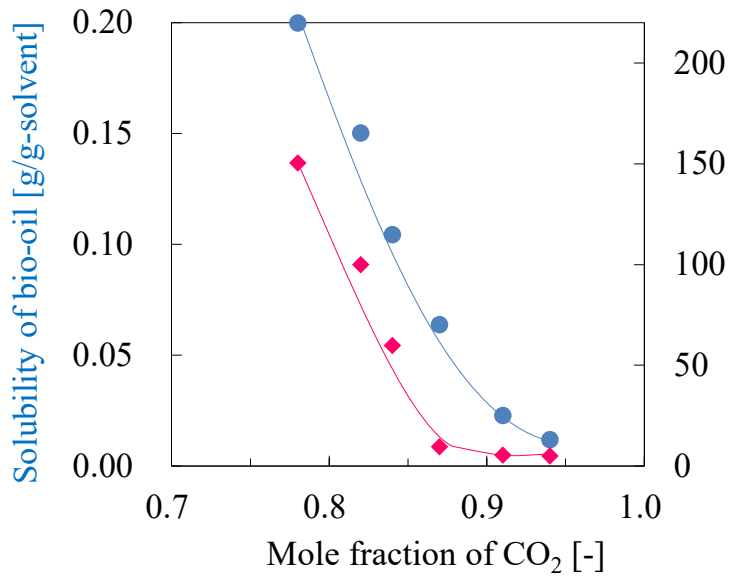

Figure 4. Influence of $\mathrm{CO}_{2}$ mole fraction in the extractant on the solubility of bio-oil and phosphorus concentration $\left(25-27^{\circ} \mathrm{C}, 5.0-5.3 \mathrm{MPa}\right)$

The solubility of bio-oil and phosphorus concentration decreased with an increase in the mole fraction of $\mathrm{CO}_{2}$ because of the decreasing solvent power of hexane. When the $\mathrm{CO}_{2}$ mole fraction was greater than or equal to 0.87 , the phosphorus concentration was lower than the target value of $20 \mathrm{ppm}$. The solubility of bio-oil extracted using 0.87 mole fraction of $\mathrm{CO}_{2}$ has good solubility and phosphorus concentration.

Figure 5 shows the change in phosphorus concentration in the extracted oil as a function of the extraction time, when extracted at $26^{\circ} \mathrm{C}, 5.1 \mathrm{MPa}$, and 0.87 mole fraction of $\mathrm{CO}_{2}$. The average phosphorus concentration in the extracted oil was $9.5 \mathrm{ppm}$, which is far beyond the phosphorus concentration of $350 \mathrm{ppm}$ in the oil extracted using hexane alone.

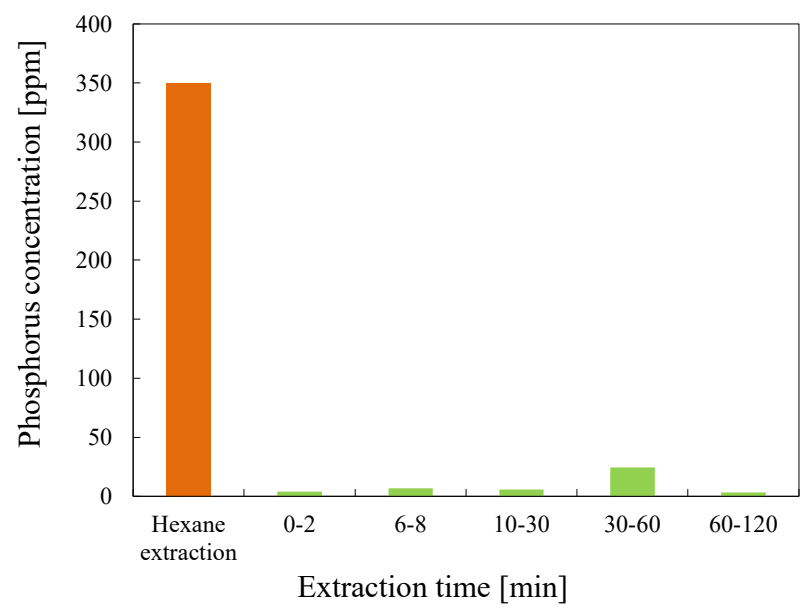

Figure 5. Change in phosphorus concentration in the extracted oil at different extraction times $\left(26^{\circ} \mathrm{C}, 5.1 \mathrm{MPa}\right.$, and 0.87 mole fraction of $\mathrm{CO}_{2}$ )

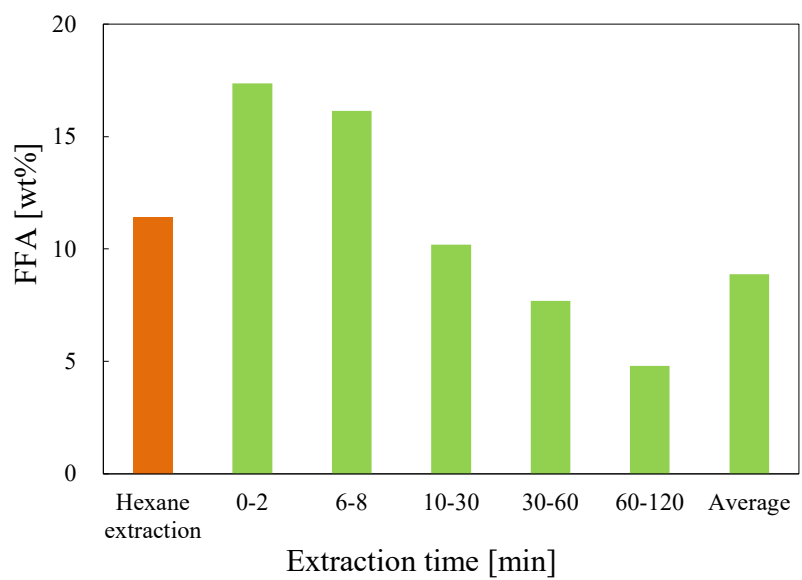

Figure 6. Change in free fatty acid concentration in the extracted oil at different extraction times $\left(26^{\circ} \mathrm{C}, 5.1 \mathrm{MPa}\right.$, and 0.87 mole fraction of $\left.\mathrm{CO}_{2}\right)$ 
Figure 6 shows the FFA concentration in the extracted oil as a function of the extraction time under the above conditions. The fatty acid concentration was higher in the early fractions of the extraction. This is because of the higher solvent selectivity for free fatty acids over the triglycerides, which are low molecular weight compounds comprising free fatty acids (Fernándeza et al., 2015). The average FFA concentration was $8.9 \mathrm{wt} \%$. This is close to $11.4 \mathrm{wt} \%$, which is the FFA concentration obtained by hexane extraction.

\section{Conclusions}

Extraction using expanded hexane with $\mathrm{CO}_{2}$ was studied as a new method to recover bio-oil from rice bran for biodiesel production. The extractions were performed in the temperature range $25-27^{\circ} \mathrm{C}$ and pressure range 5.0$5.3 \mathrm{MPa}$. It was found that the solubility of bio-oil and the phosphorus concentration decreased with increase in mole fraction of $\mathrm{CO}_{2}$. The optimum conditions, namely, $26^{\circ} \mathrm{C}$, $5.1 \mathrm{MPa}$, and 0.87 mole fraction of $\mathrm{CO}_{2}$, yields bio-oil with good solubility and phosphorus concentration less than $20 \mathrm{ppm}$. The solubility was $0.0637 \mathrm{~g} / \mathrm{g}$-solvent, phosphorus concentration was $9.5 \mathrm{ppm}$, and FFA concentration was $8.9 \mathrm{wt} \%$.

Comparing with the conventional methods, the solubility of bio-oil and the phosphorus concentration obtained using this method were found to lie between those obtained using hexane extraction and $\mathrm{SC}-\mathrm{CO}_{2}$ extraction. The yield was better than that obtained by hexane extraction and close to that obtained by using $\mathrm{SC}-\mathrm{CO}_{2}$ extraction. Finally, the FFA concentration in the extracted oil was approximately the same as that obtained with conventional methods.

\section{Acknowledgements}

This research was supported by SATREPS, JST/JICA.

\section{References}

Fernándeza, C. M., L. Fiorib, M. J. Ramosa, Á. Péreza, and J. F. Rodríguez; "Supercritical Extraction and Fraction of Jatropha Curcas L.oil for Biodiesel Production," The Journal of Supercritical Fluids, 97, 100-106 (2015)

Halim, R., M. K. Danquah, and P. A. Webley; "Extraction of Oil from Microalgae for Biodiesel Production: A Review," Biotechnology Advances, 30, 709-732 (2012)

Knapp, H., R. Döring, L. Oellrich, U. Plöcker, and J. M. Prausnitz; Vapor-Liquid Equilibria for Mixtures of Low Boiling Substances, pp. 625-626, Dechema, Frankfurt, Germany (1982)

Lakkakula, N. R., M. Liama, and T. Walker; "Rice Bran Stabilization and Rice Bran Oil Extraction Using Ohmic Heating," Bioresource Technology, 92, 157-161 (2004)

Pandey, R. and S. L. Shrivastava; "Comparative Evaluation of Rice Bran Oil Obtained with Two-step Microwave Assisted Extraction and Conventional Solvent Extraction," Journal of Food Engineering, 218, 106-114 (2018)

Tomita, K., D. Machmudah, N. Wahyudiono, R. Fukuzato, H. Kanda, A. T. Quitain, M. Sasaki, and M. Goto; "Extraction of Rice Bran Oil by Supercritical Carbon Dioxide and Solubility Consideration," Separation and Purification Technology, 125, 319-325 (2014) 